Article

\title{
How Can Blockchain Technology Accelerate Energy Efficiency Interventions? A Use Case Comparison
}

\author{
Marco Schletz ${ }^{1}$ (D) Ana Cardoso ${ }^{1}$, Gabriela Prata Dias ${ }^{1}$ and Søren Salomo ${ }^{2,3, *(D)}$ \\ 1 UNEP DTU Partnership, Department of Technology, Management and Economics, \\ Technical University of Denmark, Copenhagen Ø, 2100 Copenhagen, Denmark; macsc@dtu.dk (M.S.); \\ anacar@dtu.dk (A.C.); gdias@dtu.dk (G.P.D.) \\ 2 Technology and Innovation Management, Technical University Berlin, 10623 Berlin, Germany \\ 3 Center for Entrepreneurship, Technical University of Denmark, DTU, 2400 Kgs. Lyngby, Denmark \\ * Correspondence: salomo@tu-berlin.de; Tel.: +49-30-314-26090
}

Received: 22 September 2020; Accepted: 5 November 2020; Published: 10 November 2020

\begin{abstract}
This paper qualitatively evaluates the application of blockchain technology for three energy efficiency use cases. To achieve the Sustainable Development Agenda, energy efficiency improvements have to double by 2030. However, the adoption of energy efficiency interventions is slow due to several market barriers. Blockchain technology is a nascent technology with the potential to address these barriers or even fundamentally change energy system designs, by enabling transparent, decentralised, and tamper-resilient systems. Nevertheless, a blockchain application comes with trade-offs and needs to be considered on a case by case basis. In this paper, we examine the benefits and constraints of a blockchain application for three different approaches to achieving energy efficiency: (i) peer-to-peer (P2P) energy trading; (ii) White Certificate Scheme (WCS); and (iii) Energy Service Companies (ESCOs). For each of these cases, we apply a decision framework to assess blockchain feasibility and outline a potential blockchain-based design. The analysis shows that blockchain functions are case dependent and that an application creates different governance and system designs due to varying case characteristics. We discuss how the identified blockchain adoption barriers can be overcome and stress the need for policy action to advance the development of pilot studies. By decentralising system governance, blockchain enables innovative designs that can accelerate the implementation of energy efficiency interventions.
\end{abstract}

Keywords: energy efficiency; blockchain; market barriers; energy efficiency obligations; white certificate scheme (WCS); energy service companies (ESCOs); peer-to-peer (P2P); energy trading; decision framework

\section{Introduction}

Accelerating the adoption of energy efficiency interventions is critical to meet two objectives: First, to double the global rate of improvement in energy efficiency by 2030, as put forward by the Sustainable Development Agenda [1]. Second, to achieve the objective of the Paris Agreement of limiting global average temperature to well below $2{ }^{\circ} \mathrm{C}$ [2]. The most significant reduction in global greenhouse gas emissions is expected to come from energy efficiency savings [3]. However, the adoption of efficiency interventions is stalling as the primary energy intensity only improved by $1.2 \%$ in 2018 , which is the lowest growth rate since 2010 [4]. Similarly, the number of technical efficiency improvements almost halved between 2015 and 2018 [4]. This progress is insufficient for meeting the goals of the Paris Agreement and the 2030 Agenda [5].

Presently, investments in efficiency interventions are constrained by economic, financial, informational, and regulatory barriers. Barriers like lack of access to capital, high investment costs, 
inflated risk perceptions, and high transaction costs [5-9] impair the financing of efficiency interventions in many countries. As a consequence, efficiency investments have largely stalled since 2014 [4], while investments would need to double by 2025 to comply with the goals of the Paris Agreement and the 2030 Agenda [5]. Private investment is critical for pushing efficiency investments forward, especially in developing countries where access to financing is extremely limited [10,11]. Informational barriers related to the cost and benefits of an efficiency intervention and a lack of comprehensive measurement and verification methodologies $[8,12]$ lead to a lack of credible information $[6,9]$. This lack of credible information inhibits the development of policies and limits investments to accelerate the implementation of efficiency interventions. Peimani [13] showed that due to the low availability and trustworthiness of information, financial institutions perceive the investment in efficiency interventions as high risk and low return.

Considering these barriers, blockchain technology could provide an innovative approach to create transparency and reduce transaction costs of energy efficiency interventions. Downes and Reed [14] consequently propose that blockchain technology could disrupt difficult and time-consuming traditional governance models to improve sustainability outcomes. By distributing data across a network of actors, blockchain can eliminate information asymmetry and create novel platforms for interactions. In the context of energy efficiency, the literature suggests blockchain technology to be relevant in mainly three application areas. First, blockchain could enable innovative energy trading systems, such as P2P energy trading [15-30], electric vehicle charging [15,31] and energy markets $[22,27,32-35]$. Second, blockchain could serve as a distributed accounting and trading platform for the energy efficiency White Certificate Schemes (WCS) [15]. Third, blockchain could enable decentralised financing mechanisms for Energy Service Companies (ESCOs) [15,36,37].

Although there is agreement on the general potential of blockchain technologies for the different energy efficiency application areas, no study conducts a systematic assessment and comparison of these different application scenarios. Given the scenario diversity, it is critical to understand when a blockchain application is beneficial and how different criteria lead to changes in the blockchain design and governance. This paper presents the first step towards academic energy efficiency research to evaluate the potential and unclear effects of this potentially disruptive technology. For this, incremental research is required to better understand, predict and design blockchain applications that benefit energy efficiency interventions [38]. The paper seeks to initiate a discussion by educating policymakers and practitioners on the potential benefits of the technology. This discussion is important for opening up this field of research to keep up with state-of-the-art research in other disciplines, such as healthcare $[39,40]$ or supply chain $[38,41]$. For this discussion, the paper provides the following contributions: It uses a decision framework to qualitatively evaluate whether a blockchain application is technologically feasible for each case. The findings from these analyses are then compared to show the differences in system organisation and governance, as well as benefits and barriers, among the cases. Furthermore, we illustrate a possible blockchain design for each application area. Finally, we discuss how the identified blockchain adoption barriers can be overcome and stress the need for policy action to advance the development of pilot studies.

The paper is divided into four sections. Section 2 presents general blockchain concepts relevant to the theoretical background of the paper. Section 3presents the analysis of each use case and illustrates a potential blockchain design. Section 4 compares the case findings and discusses the differences. Section 5 concludes this paper with recommendations on how to develop the application of this nascent technology in the energy sector.

\section{Blockchain Concepts}

Blockchain (also known as Distributed Ledger Technology, or DLT) is a novel form of data storage where all data is shared across the network participants. These participants are represented by network nodes that store, verify, transfer, and communicate data [34]. Through these nodes, each participant has access to the ledger, i.e., the full history of network transactions [42,43]. Nodes operate 
under the consensus rules of the blockchain network. The mechanism establishes consensus among the network nodes if a new transaction complies with the network rules and is valid considering the ledger history [44]. In blockchain systems, the valid transactions are aggregated in a "block" and then cryptographically linked to the existing chronological "chain" of blocks in the ledger [45]. The combination of cryptography, time-stamping and hashing of all transactions makes the ledger history tamper-resilient and very difficult to defraud [27,46].

There exists a range of blockchain archetypes with diverse governance mechanisms, ranging from private permissioned to public permissioned, to public permissionless blockchains [47-49]. The distinction between permissioned and permissionless blockchain systems is determined on the accessibility of the consensus mechanism [50]. In a permissionless blockchain, there are no restrictions on who can become a network node, whereas in private and permissioned systems, only preregistered nodes approved by a central authority can communicate and validate network transactions [51]. The categorisation between public and private depends on the access to the ledger information. In a private system, the information is only available to predefined users [51]. These different blockchain archetypes not only differ in their governance design, but also in their performance features [15,32]. In general, private and permissioned systems consist of fewer nodes, which increases their performance in terms of throughput and scalability. Permissionless systems consist of a higher number of network nodes, which makes the system more decentralised.

Blockchain acts as a platform for combining different emerging technologies into a trusted data layer. Internet of Things (IoT) can automate the data capture from the source or remotely (e.g., using smart meters or remote sensing technologies [52-54]), while machine learning can improve data verification, the identification of data errors, and fraudulent behaviour [55-58]. Blockchain automates the dissemination and synchronisation of this trusted data across a network of participants and provides a tamper-resilient and immutable log. These features enable parties to transact directly, eliminating the need for a trusted, authoritative third party, and thereby eliminating the single point of control over the entire ledger [14].

Smart contracts are an essential part of this blockchain-based platform as they enable the integration of other emerging technologies and enable the automated execution of contract actions if specific predefined requirements are satisfied $[42,52,59]$. These smart contracts are programmable computer codes formulated as 'if this is true, then...' statements and can automatically and consistently enforce regulations and methodologies to ensure transparency and accountability [60]. This automation further reduces costs and increases the flow of information by removing intermediaries such as verifiers and auditors [61].

\section{Use Case Analysis}

Based on the blockchain application areas suggested in the literature, we select three dominant energy efficiency use cases to test whether a blockchain application is feasible and outline a possible blockchain design. The selected cases are P2P energy trading, as it is by far the most prominent research topic within the energy trading systems [15-21,23-30]. We consider P2P energy trading as a valid case, as the inserting of renewable energy increases system efficiency, particularly regarding the significant potential of IoT devices to improve grid and load management $[15,30,49,62,63]$. We complement the P2P trading case with the White Certification Scheme (WCS) and ESCO financing of energy efficiency interventions $[9,15,64]$. Such an assessment and comparison of energy use cases is a novel contribution to the literature on energy efficiency.

It is essential to consider that blockchains are not a panacea for all use cases, but an application needs to be carefully evaluated as the application comes with considerable costs and trade-offs. Compared to a centralised database, blockchain is a highly inefficient technology because of its much slower and stricter developing and updating processes $[48,65,66]$. Additionally, blockchain technology has the inherent trade-off between maximising for scalability, security and decentralisation, 
the so-called trilemma $[55,67]$. This blockchain trilemma connotes that it is possible to increase any one or two of these objectives, but this will, in return, inevitably reduce the third objective.

To assess the feasibility of a blockchain application each of the three use cases, we apply a decision pathway developed by Schletz et al. [55]. This pathway consists of eight distinct classifiers phrased as consecutive questions. The first three questions assess the general applicability of a blockchain, which are followed by three questions regarding the governance and data-accessibility specifications, and the last two questions determining the most suitable type of blockchain system.

\subsection{Peer-to-Peer (P2P) Energy Trading}

Traditional power systems follow a centralised approach, which is primarily challenged by the changing dynamics between prosumers $[16,19,27,63,68]$. In this context, prosumers are proactive consumers that actively manage their consumption, generation and storage of energy [21,69]. Prosumers can thus appear as both consumers and producers during different times, depending on their energy production and consumption patterns.

Traditional centralised systems cause pricing inefficiencies, as customers are charged with a single, fixed-rate, despite actual energy costs varying depending on supply and demand dynamics in real-time $[30,33]$. Additionally, energy systems are increasing in complexity with different forms of energy production and a higher number of participants, which poses challenges related to the control and management of distributed sustainable energy forms [33]. The increasing complexity of actors and possible actions, leading to a demand for advanced communication and data exchange, makes central management and operation of energy systems more and more difficult [27].

By enabling decentralised energy production, consumption, and P2P transactions, consumers may be better incentivised to invest in efficient and clean technologies [70]. The blockchain-enabled decentralised grid operation leads to much lower costs due to a simplified trading framework, sets up real-time energy markets and enables privacy-preserving transactions [71-73]. Distributed energy systems can re-introduce competition along the energy supply chain, which promotes efficiency and reduces costs $[49,74-76]$. Such a system can reduce power outages by providing decentralised local alternative sources to the central utility provider [49]. Innovative decentralised approaches and designs may offer the advantage of enabling the proliferation of prosumers, resulting in reduced electricity costs and increased price competitiveness of distributed power sources [17]. Through the integration of P2P mini-grids, local generation and demand are better managed and balanced, which also facilitates the penetration of larger volumes of renewable energy resources in the grid [77]. The declining costs of rooftop solar and battery combined with smart devices, which give prosumers the ability to manage their energy needs and have already resulted in a decline of the total load demand [78]. In a developing country context, with energy access limitations, decentralisation based on solar or wind is often the way to electrify remote parts of the country, because it is cheaper, more flexible and faster than centralised power plant construction and grid extensions [79-81].

In this context, emerging technologies such as IoT devices and blockchain are considered enablers for the creation of decentralised and democratised energy systems [15,82]. The integration of IoT devices reduce the need for human resources and improve accuracy by creating intelligent systems that can monitor and communicate with each other [71]. Emerging IoT smart metering devices provide live energy demand and supply data and are capable of reacting to pre-set or real-time energy production and consumption $[17,27,33]$. An alternative example of a non-blockchain-based application of time of use tariffs is, for example, the Octopus.energy system (more information available at: https://octopus.energy/agile/ (accessed on 25 October 2020)). Better information on expected energy transaction constitutes valuable information for more efficient grid supervision from distributed system operators [68]. However, this interconnection of suppliers and consumers in the form of decentralisation P2P energy trading currently suffers from issues of trust, security and inefficiency [30]. These constraints are suggested by the literature to be addressed by blockchain technology and smart contracts. [19,23,26,28,30,32,33]. In addition, blockchain provides more robust privacy features. 
While in other examples the utility or Octopus.energy has access to the prosumers own smart meter. Blockchain protects this sensitive IoT data $[83,84]$ while simultaneously mitigating issues of data integrity and availability arising in the IoT $[85,86]$. For example, Aitzhan and Svetinovic [29] developed a blockchain prototype to enable private decentralised energy trading, which provided higher privacy and security compared to the traditional centralised trading solutions.

The combination of IoT devices with smart contracts can autonomously enforce the terms of the contract and automates the settlement, which significantly reduces transaction costs and introduces near real-time settlement $[15,28,33,85,87,88]$. The energy trading process contains security risk such as fake energy bids, selling unavailable energy, a false commitment by buyers, double spending energy/money, or not delivering an already sold energy [16]. The blockchain can enforce the terms of the contract by verifying the validity of energy bids, and that claimed energy exists before posting the sales order. After the order is settled, the smart meter receives a message from the smart contract to automatically release the energy to the buyer [16].

Figure 1 illustrates our proposed design for a blockchain-based P2P energy trading system.

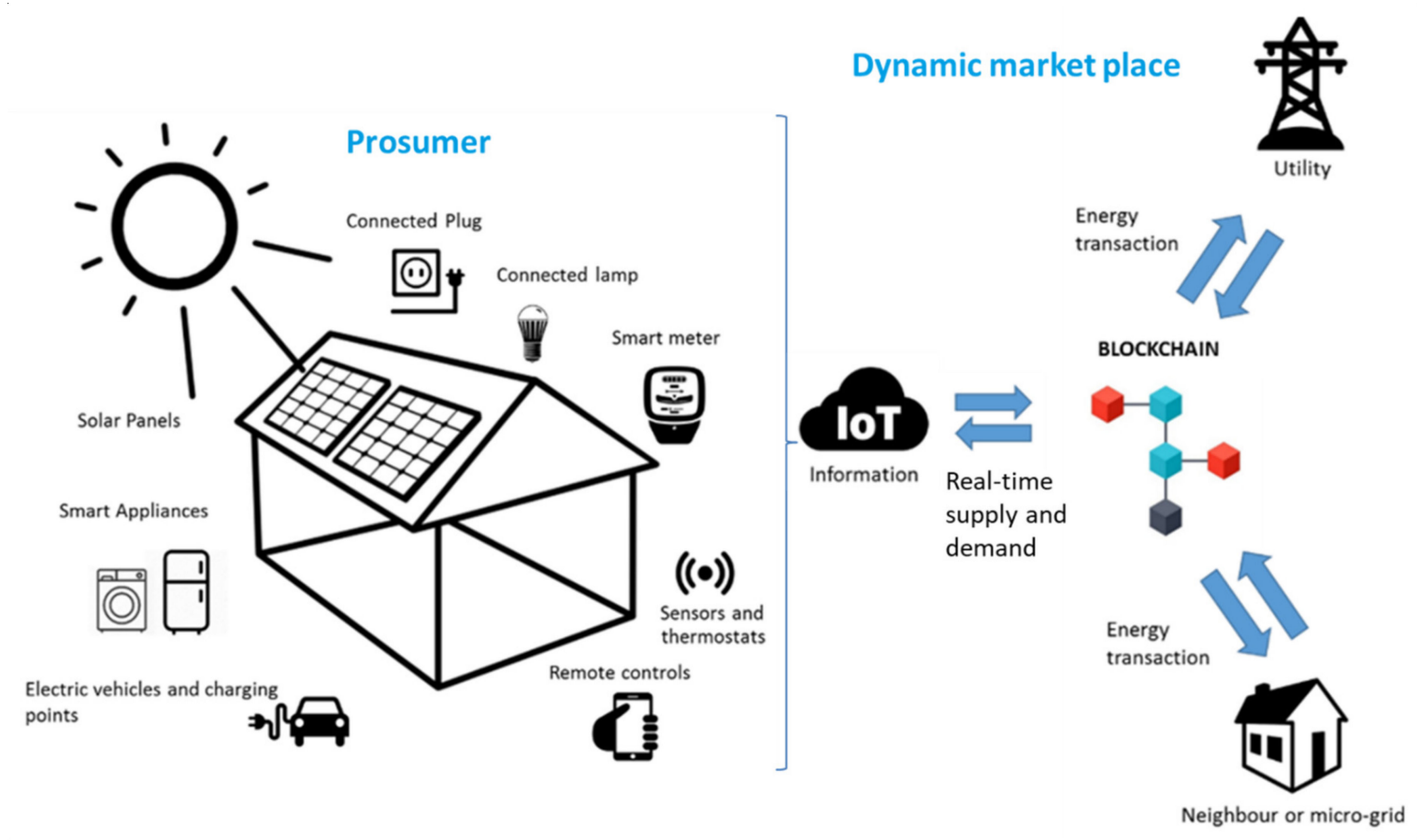

Figure 1. Blockchain-based decentralised P2P energy trading system.

The IoT devices collect and assess the real-time energy demand and generation of the prosumer. When the prosumer generates surplus energy, this surplus is transmitted to the local grid and sold on the blockchain-based market place to another local prosumer in demand for energy. When the prosumer has energy demand, the IoT devices automatically purchase the needed energy on the blockchain market or reduce the energy demand by powering down and turning off devices. The IoT devices react to the energy price dynamics by using more energy during low-cost periods and using less energy during high-cost periods. In this way, the IoT devices allow adjusting energy use over the day while delivering end-user services (e.g., cold or warm air, hot water, electric vehicle charging) at the same or better quality and with lower costs associated.

The consumption adjustments result in a continuous reshaping of the prosumer's demand profile [89]. The reshaping is invisible to the prosumer but leverages more granular rate structures that monetise demand flexibility's capability to reduce costs both for the prosumers and the grid $[17,90]$. Through the reshaping, the grid increases energy efficiency as the expensive and inefficient peak load periods are reduced and shortened. 
The blockchain ledger records all energy kilowatt-hour transactions and enables flexible prices. Consequently, prosumers are no longer charged with an average price but specifically with a flexible price according to the time of use. This flexible cost provides direct feedback to prosumers, possibly leading to improved energy consumption behaviours.

To assess the feasibility of applying a blockchain solution to this design, we apply the decision framework developed by Schletz et al. [55], which is shown in Table 1.

Table 1. Evaluation of the feasibility of applying a blockchain solution for P2P energy trading.

\begin{tabular}{cc}
\hline \multicolumn{1}{c}{ Question } & Response \\
\hline $\begin{array}{c}\text { 1. Are there multiple actors with } \\
\text { distinct interests contributing? }\end{array}$ & $\begin{array}{c}\text { Yes. There is a (potentially) high number of individual energy } \\
\text { prosumers participating in a network. Additionally, other actors, like } \\
\text { the local utility and public actors, can be part of the network. }\end{array}$ \\
\hline $\begin{array}{c}\text { 2. Is there a digitally } \\
\text { representable asset? }\end{array}$ & $\begin{array}{r}\text { Yes. The energy data collected from the IoT devices are digital and can } \\
\text { be processed by the blockchain-based smart contracts. }\end{array}$ \\
$\begin{array}{c}\text { 3. Is there a need for a final and } \\
\text { immutable transaction record? }\end{array}$ & $\begin{array}{c}\text { Yes. As the network acts as a decentralised energy market for the } \\
\text { prosumers, there is a need for complete transaction history. } \\
\text { purposes and the monitoring and certification of renewable } \\
\text { energy certificates. }\end{array}$ \\
\hline
\end{tabular}

No. For the considered P2P mini-grids, the transaction volumes do not pose a scalability challenge. In potential future large-scale blockchain

4. Are there high expected transaction volumes?
P2P systems, there could be scalability limitations as per the blockchain trilemma. However, such scalability limitations are continuously improved. Additionally, it is essential to consider, for example, the frequency of smart meter data uploads to reduce the transaction volume in the system design. It is further recommended to only store small-sized numerical data on the blockchain.

Yes. The role of the utility is reduced through decentralised blockchain-and IoT-based coordination, which provides valuable

5. Is there a potential for removing intermediaries? information for more efficient grid supervision from distributed system operators [68]. This interconnection of prosumers through P2P energy trading offers close to real-time energy production and consumption for more efficient grid coordination $[17,27,33]$.

Yes. The seller and the buyer of energy have contrary incentives to alter the amount of documented energy in their favour. The issuance of renewable energy certificates creates another potential incentive to increase the amount of documented energy generation further.

6. Are there conflicting incentives or interests between actors?

Besides, the utility has an incentive to reduce P2P transactions to keep its margin and in some cases, its energy production monopoly.

No. The transactions are primarily private between prosumers,

7. Should there be full data transparency towards external actors? with interest to protect this sensitive data. Additionally, public authority and the utility should have access to the data to determine the status of the energy network and identify potential shortfalls.

No. For a decentralised energy system to evolve, it is essential to keep the barrier to entry for prosumers as low as possible. Every prosumer interested in P2P energy trading should have access to the network. Of course, this needs to comply with regulatory requirements, so based on national circumstances, it is unlikely for prosumers to be able to stay anonymous or pseudonymous.

The assessment presented above shows that a blockchain application is generally feasible. Although this application area is the well discussed in academic literature as an attractive use case (see, e.g., [15,19,23,26,27,30,33,70,91]) blockchain-based P2P energy trading is still only at a concept or prototype stage concerning its actual application in practice [15]. The main technical challenge for 
this system is to balance the blockchain trade-offs to provide the required scalability and transaction throughput, while simultaneously not compromising the systems cost-efficiency, decentralisation and security $[19,23,27]$. In the decision framework analysis, we find that a private permissionless blockchain is most applicable. With this, we mean that everyone has access to the network, but the specific transaction data is anonymous or private. Most P2P case studies currently use a form of Ethereum with privacy features [15,16,23,28]. Di Silvestre et al. [22] further outline and discuss multiple other blockchains, such as Tendermint, Multichain and Hyperledger Fabric for this case. An alternative is the Power Ledger platform (more information available at: https://www.powerledger.io/ (accessed on 23 May 2020)), where every prosumer can get access through the Power Ledger Token (POWR) token. However, these blockchains are only examples, and we seek to remain blockchain agnostic due to the rapidly evolving blockchain ecosystem, which might render any specific blockchain soon outdated.

For now, as P2P energy trading mainly improves local energy systems [27], so that scalability considerations do not pose a severe limitation. However, if a large-scale adoption of P2P trading occurs, scalability might become a limiting factor. Additionally, blockchain scalability is continuously improved. As an example, the most recent Ethereum 2.0 design uses a different consensus mechanism (Proof of Stake instead of Proof of Work) and 'sharding' as a mechanism to 'drastically' improve the throughput of the Ethereum blockchain [92]. Similarly, based on several architectural optimisations, Hyperledger Fabric can improve the end-to-end throughput from 3000 to 20,000 transactions per second [93].

Given the advantages presented for this use case and its general technical feasibility, we evaluate a blockchain application as promising.

\subsection{White Certificate Scheme (WCS) Case Study}

The white certificate scheme (WCS) creates a flexible market-based mechanism to incentivise energy efficiency improvements. The regulatory authority of the WCS creates an obligation for energy and gas distributors with more than 50,000 clients to annually increase their energy efficiency rate $[9,64]$. In the European Union, the Energy Efficiency Directive [94] introduces an energy efficiency target of $32.5 \%$ for 2030 and establishes the objective of reducing energy demand by $1.5 \%$ per year. The WCS is a vital incentive mechanism and is applied in several European countries, such as France, Italy, Denmark [95], and the Australian states of New South Wales and Victoria, which have the oldest schemes in place. Figure 2 illustrates a traditional national WCS model.

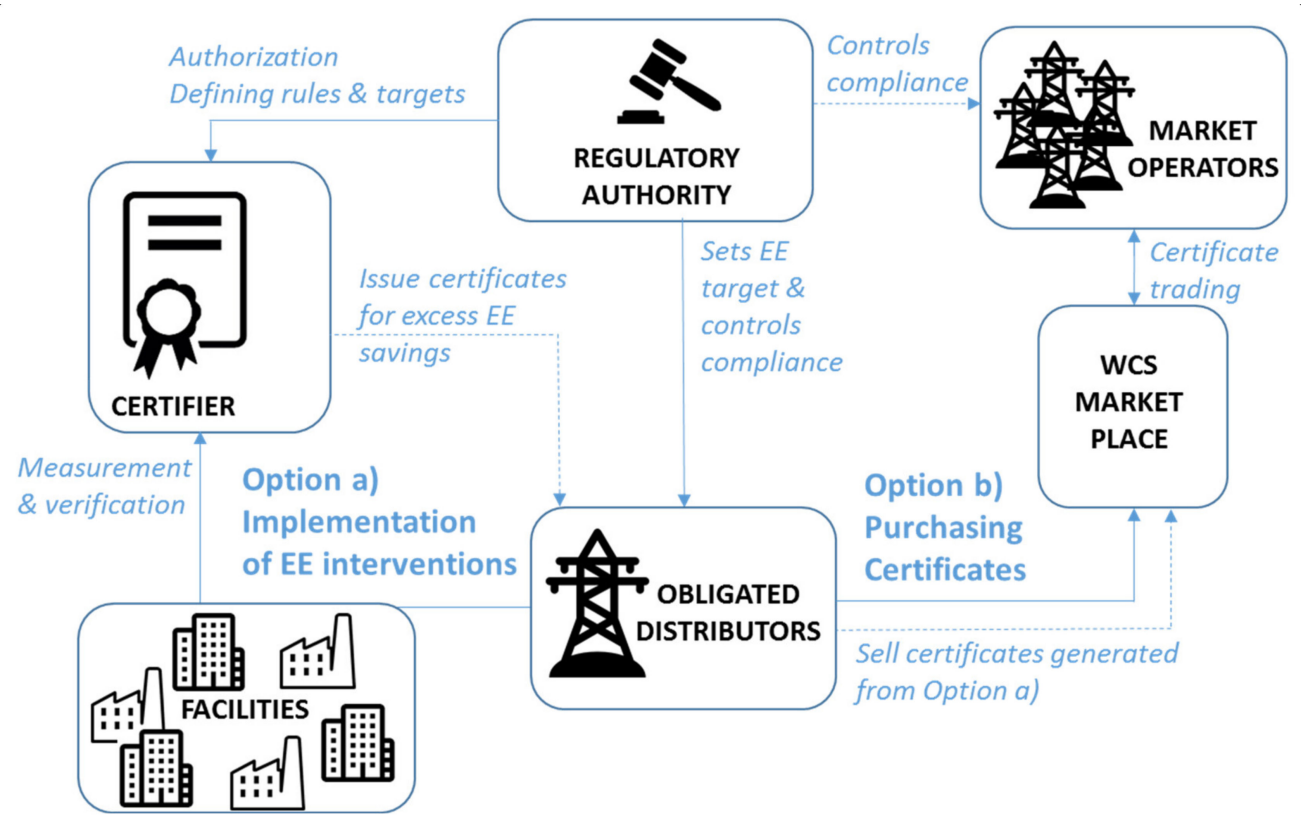

Figure 2. The traditional model of a national WCS. 
The national regulatory authority is a government institution (e.g., the Ministry of Environment), which sets an energy efficiency target for each of the obligated distributors. To comply with these targets, the distributor has two choices: a) to implement energy efficiency interventions in the energy production facilities, or b) to acquire white certificates on the WCS market. If the implemented interventions (option a) generate efficiency savings in excess of the individual distributor's target, these excess savings can be converted to white certificates and sold on the WCS market. The unit of the white certificate is one ton of oil equivalent (toe), and the price of these certificates varies based on the market dynamics [64]. The WCS market enables the most cost-effective achievement of the national targets by allowing all operators to exchange certificates.

Other market operators selling certificates on the WCS market are non-obligated distributors, ESCOs, or another company conducting efficiency measures. ESCOs alone supplied $78 \%$ of all certificates in the Italian scheme in 2015 [96]. The regulatory authority selects a technical certifier that validates and certifies the energy efficiency interventions of obligated distributors and the other market operators and issue the respective WCS. The regulatory authority also sets the rules for the certifier and punishes obligated operators that fail to comply with their efficiency targets.

Presently, the certificates are suffering from a lack of transparency in the measurement and verification process [15], as well as from a lack of credible information sources [6,9]. These information barriers have multiple adverse effects: First, the lack of quality information hinders investors in conducting a proper analysis of revenue potentials from certificate sales, which are significantly negative for investments in small and medium-sized enterprises (SMEs) [6,9]. Second, the transaction costs associated with centralised information collection, evaluation, and control for certificate issuance are high. The public company operating the Italian WCS alone incurred costs of Euro 14 million in 2016 [64]. Finally, several WCS frauds were recently unveiled. In Italy, a WCS fraud with a provisional value of Euro 700 million was discovered in 2017, of which Euro 105 million were already obtained [64]. In France, a large number of fraud cases was found in 2017, with "tens of millions of Euros at stake" [97]. This traditional centralised system requires trust in the system operator and poses the risk of outages and data losses [98-100].

In contrast, blockchain-based systems provide a reliable database for multiple parties with properties such as data integrity, availability, accessibility, efficient reading, and immutability [100]. In addition to these blockchain features, the technology also facilitates the integration and management of IoT device data without centralised control [85,101]. The programmable logic enforced by blockchain-based smart contracts automatic enforces the network rules for awarding white certificates, based on the data inputs provided by the IoT devices. The automation of data collection (IoT devices) and automatic issuance of certificates reduce administration transaction costs significantly. Through this, it facilitates the issuance and transaction of certificates among obligated distributors operating, for example, in a Europe-wide WCS market. Figure 3 illustrates our proposed model of blockchain-based WCS.

Blockchain-based smart contracts can address the lack of transparency and reliable data by automating data collection through the integration of a smart meter that measures the energy consumption of the facility $[102,103]$. This improved transparency increases the availability of credible information and enables the traceability of the origin of the white certificate and the corresponding energy consumption data. The smart meter continuously collects the energy consumption of the facility and automatically generates the certificates based on the energy savings calculated from the data collected by the smart meter in comparison to the energy consumption baseline. However, IoT devices are currently costly, and their application can be limited by a lack of skilled people and limited internet access in rural areas [65]. Furthermore, smart meters and the transmission of data from these smart meters can be manipulated and need to be protected from tampering $[29,45]$. 


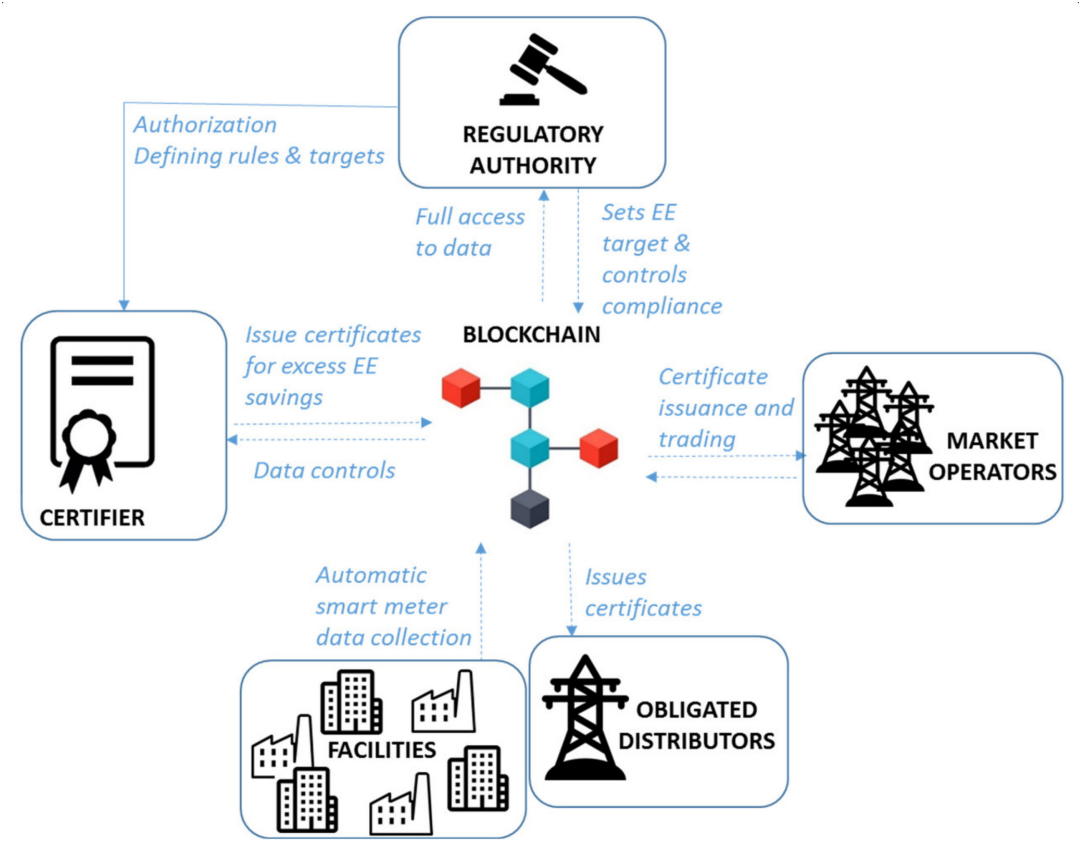

Figure 3. Blockchain-based model of a national WCS.

The regulatory authority has full access to all current information, which allows proactive policy action to achieve energy efficiency targets. Using a blockchain-based market place reduces costs, increases transparency as each certificate can be traced back to the specific smart meter data, and the process is faster as data does not have to be transferred manually between different entities [15]. Additionally, the blockchain-based system prevents double-counting as the ownership is deterministic, meaning that one actor can only own the certificate at each point in time. This deterministic ownership makes it very easy for the regulatory authority to identify non-compliant distributors.

Similarly to the P2P energy use case, we systematically assess the feasibility of applying a blockchain solution, which is shown in Table 2.

Table 2. Evaluation of the feasibility of applying a blockchain solution to the WCS case.

\begin{tabular}{cc}
\hline \multicolumn{1}{c}{ Question } & Response \\
\hline $\begin{array}{c}\text { 1. Are there multiple actors with } \\
\text { distinct interests contributing? }\end{array}$ & Yes. As illustrated in Figure 2, there are multiple actor groups involved \\
in the network.
\end{tabular}


Table 2. Cont.

\begin{tabular}{|c|c|}
\hline Question & Response \\
\hline $\begin{array}{l}\text { 5. Is there a potential for removing } \\
\text { intermediaries? }\end{array}$ & $\begin{array}{l}\text { Yes. The role of the certifier can be minimised and focused on } \\
\text { preventing tampering through automated data collection with IoT } \\
\text { devices, such as smart meters. Furthermore, the market place operator is } \\
\text { removed as the function is directly integrated into the blockchain-based } \\
\text { data system. Disintermediation increases the speed of data flow and } \\
\text { eliminates information asymmetry between the various actors. } \\
\text { By reducing the roles of multiple intermediaries, and thus reducing } \\
\text { transaction costs, the higher resource cost associated with a blockchain } \\
\text { application is more than offset }[52,105,106] \text {. }\end{array}$ \\
\hline $\begin{array}{l}\text { 6. Are there conflicting incentives } \\
\text { or interests between actors? }\end{array}$ & $\begin{array}{l}\text { Yes. Particularly the facilities and obligated distributors have an } \\
\text { economic incentive to increase their number of certificates for } \\
\text { complying with their efficiency targets and selling excess certificate on } \\
\text { the market. Enhanced transparency and auditability features are } \\
\text { particularly important in light of the recent WCS frauds. }\end{array}$ \\
\hline $\begin{array}{l}\text { 7. Should there be full data } \\
\text { transparency towards } \\
\text { external actors? }\end{array}$ & $\begin{array}{l}\text { No. As the system handles sensitive commercial data, the transaction } \\
\text { data should not be publicly accessible. All information only needs to be } \\
\text { available for the certifier and the regulatory authority so that they can } \\
\text { verify and issue the correct amount of certificates. It is also essential to } \\
\text { protect sensitive operational data from the facilities and } \\
\text { obligated distributors. }\end{array}$ \\
\hline $\begin{array}{l}\text { 8. Should there be permissioned } \\
\text { access to the system? }\end{array}$ & $\begin{array}{l}\text { Yes. Only the defined group of actors in Figure } 2 \text { need to have access to } \\
\text { the network. A permissionless system is often too risky for a } \\
\text { governmental system or system with highly regulated actors, as any } \\
\text { authority does not control the system }[50,52] \text {. There are also no benefits } \\
\text { to allowing network access for external actors, as the regulatory } \\
\text { authority has the decision-making authority over the network. }\end{array}$ \\
\hline
\end{tabular}

The assessment shows that a blockchain application is technologically feasible. However, there remain several technological challenges, such as standardisation, complexity, costs, and skill requirements [15]. Blockchain, in combination with smart meters, can enhance traceability, accountability, and data visibility, which reduces the risk of fraud and provides investors with more reliable information. As pointed out in classifier 5 , there remains a need for a trusted third party or auditor to identify tampering [27]. However, the auditing can be improved through blockchains transparency and auditability features to spot fraudulent activities [42,107-109]. Ideally, data collection and verification processes are automated through emerging technologies, like IoT sensors and machine learning. With the growing availability of data, machine learning can conduct automatic tampering tests and detect fraudulent behaviour at an increasing rate.

A blockchain-based WCS can create a more dynamic market place by shortening the data feedback cycle, preventing the double-spending problem and potentially reducing intermediary costs. Given the increasing amount of pilot projects and the great potential to address the present barriers of the traditional system, a blockchain-based WCS system appears to be promising. Based on the framework analysis, we find a private permissioned blockchain most suitable. Examples for such blockchain types are Hyperledger Fabric or Ethereum Proof-of-Authority (more information available at: https://www.hyperledger.org/use/fabric and https://azure.microsoft.com/en-us/blog/ethereum-proofof-authority-on-azure/ (both accessed on 27 October 2020)). Franke et al. [50] provided an in-depth comparison between these two blockchains. However, these specific blockchains are only examples, and we seek to remain blockchain agnostic due to the rapidly evolving blockchain ecosystem that might render any specific blockchain soon outdated. 


\subsection{Energy Service Companies (ESCOs)}

ESCOs operate through energy performance contracting with their customers. The ESCO assesses the potential for renewable energies or energy efficiency interventions and finances the project, which may be the object of a loan by the ESCO. With the energy savings accrued, the customer will repay the project fees to the ESCO [110]. In the traditional model (Figure 4), the customer does not have to cover any upfront costs, as the ESCO finances the costs for equipment purchases and installations of the energy efficiency intervention. The ESCO is then reimbursed by the customer over time, based on the energy savings incurred. However, raising capital for energy performance contracting is a significant hurdle to the growth of many ESCOs. A bank or financial institution may be involved in financing the upfront investment for the purchase and installation. In this case, the bank is also receiving a share of the payments made by the customer. Only $10 \%$ of all ESCOs incorporate external financing, as banks appear to be hesitant to lending for the purpose and view associated transaction costs as being too high [111]. Consequently, limited access to finance remains a significant barrier to scaling up the activity of ESCOs $[9,36]$.

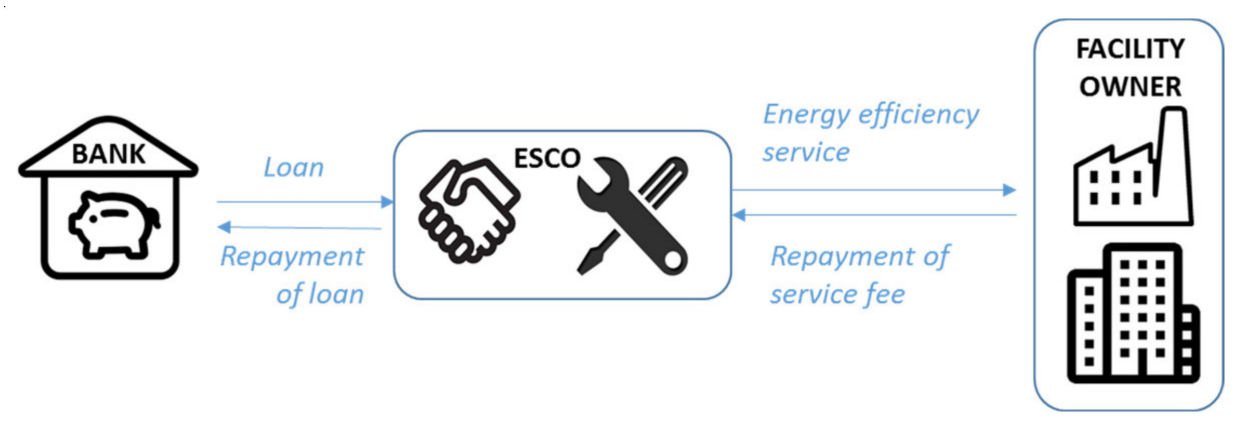

Figure 4. The traditional model of an ESCO.

In this case, a blockchain-based system can enable new financing mechanisms by enabling access to a global investor base. Blockchains enable this disintermediation of the bank as the sole potential investor as a reliable database for multiple parties with properties such as data integrity, availability, accessibility, efficient reading, and immutability [100]. These so-called tokenisation mechanisms can facilitate access to finance for the ESCO company. Blockchain-based tokenised securities represent the legal ownership of an asset, a debt-instrument or an equity share [45]. Tokens have emerged as a blockchain artefact to digitally represent an asset, a utility or a claim inherent to a blockchain project [112]. These tokens are freely divisible and transferable, which makes them ideal for executing transfers of ownership and value [113].

By enabling the aggregation of investments from a large number of investors, tokenisation can facilitate the flow of private financing to small companies. This aggregation of investments allows for a more efficient allocation of capital and increases inclusiveness because private investors, including retail investors, can directly or indirectly fund small companies that are unable to access funding otherwise [114]. The investors receive security tokens representing their share in the ESCO project, which is equivalent to their financial contribution to the particular project. The coupon payments are automatically transferred through smart contracts back to the token holders, reducing transaction costs (Figure 5). 


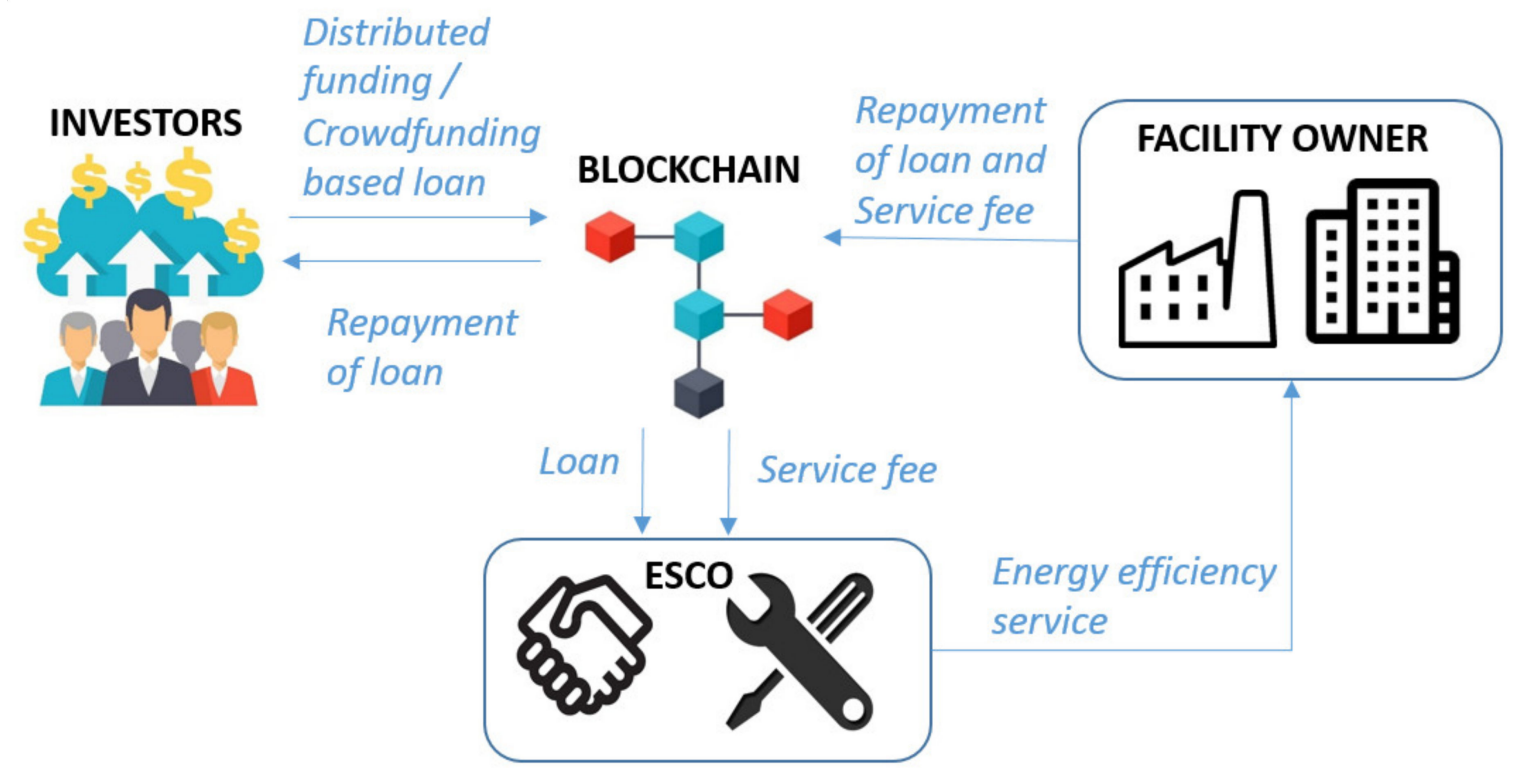

Figure 5. Blockchain-based mode of operation of an ESCO.

The ESCO raises funds for the project through a so-called Security Token Offering (STO). Once the required funds are collected, the smart contract transfers the funds to the ESCO company. The ESCO performs the energy efficiency service, and a smart meter takes stock of the energy savings accrued. The facility owner pays a fixed amount for the energy bill, and the savings accrued from the energy efficiency intervention are used for the coupon repayment and the service fee of the ESCO. A smart contract connected to the smart meter regularly transfers the coupon to the token holders, following the contractual terms. The contract expires when the facility owner pays the service fee to the ESCO and fully repays the initial funds invested, plus the interest to the STO investors. Smart meters can pose a weak link for manipulation and need to be sealed to achieve tamper resistance [29]. The registry with all the transactions is replicated through the blockchain network, which makes it traceable, secure, and tamper-proof [115].

For an assessment of the feasibility of applying a blockchain solution, we again follow the systematic decision framework, which is shown in Table 3.

The assessment shows that a blockchain application is technologically feasible and fits the use case requirements. Tokenised securities facilitate financial inclusion of a variety of actors and reduce the transaction costs for the ESCO project. Moreover, these tokens allow private (retail) investors to access financial investments that otherwise would not be available for them due to their insufficient investment size. The disintermediation of commercial banks reduces the cost of lending and diversifies access to funding by making a global investor base available [45]. Additionally, SME issuers receive access to capital, for smaller investment sizes and at affordable rates, which is not sufficiently offered by the currently available options. Tokenisation can thus address both supply and demand-side issues to accelerate investments into energy efficiency interventions related to ESCO projects. Similarly to the WCS case, we find a private permissioned blockchain like Hyperledger Fabric or Ethereum Proof-of-Authority most suitable. 
Table 3. Evaluation of the feasibility of applying a blockchain solution for the ESCO case study.

\begin{tabular}{|c|c|}
\hline Question & Response \\
\hline $\begin{array}{l}\text { 1. Are there multiple actors with } \\
\text { distinct interests contributing? }\end{array}$ & $\begin{array}{l}\text { Yes. There are at least three actor groups involved; the customer, } \\
\text { the ESCO company and the investor. }\end{array}$ \\
\hline $\begin{array}{l}\text { 2. Is there a digitally } \\
\text { representable asset? }\end{array}$ & $\begin{array}{l}\text { Yes. The asset is energy efficiency savings that are settled through the } \\
\text { transfer of a cryptocurrency. The documentation and transfer are } \\
\text { conducted on a blockchain platform. }\end{array}$ \\
\hline $\begin{array}{l}\text { 3. Is there a need for a final and } \\
\text { immutable transaction record? }\end{array}$ & $\begin{array}{l}\text { Yes. As the network acts as a financial platform between the customer, } \\
\text { the ESCO company and the investor. Accordingly, there is a need for } \\
\text { complete transaction history. This transaction log can also be used for } \\
\text { auditing purposes and the monitoring and certification of related } \\
\text { white certificates. }\end{array}$ \\
\hline $\begin{array}{l}\text { 4. Are there high expected } \\
\text { transaction volumes? }\end{array}$ & $\begin{array}{l}\text { No. Depending on the frequency of documentation of energy efficiency } \\
\text { savings (usually monthly to quarterly), the transaction volume does not } \\
\text { pose a limiting factor. }\end{array}$ \\
\hline $\begin{array}{l}\text { 5. Is there a potential for removing } \\
\text { intermediaries? }\end{array}$ & $\begin{array}{l}\text { Yes. The dependence on commercial banks is alleviated by including a } \\
\text { larger investor base of (private) investors. Additionally, auditing and } \\
\text { certification costs can be reduced through automated data collection and } \\
\text { enhanced transparency. This disintermediation reduces transaction } \\
\text { costs significantly, which offsets the higher resource costs of the } \\
\text { blockchain consensus protocol }[52,105,106] .\end{array}$ \\
\hline $\begin{array}{l}\text { 6. Are there conflicting incentives } \\
\text { or interests between actors? }\end{array}$ & $\begin{array}{l}\text { Yes. As the investors are distributed globally, they are relying on } \\
\text { traceable and transparent to verify the accurate repayment of their } \\
\text { investment. Without a robust transparency system, customers might be } \\
\text { incentivised to engage in fraudulent behaviour to reduce the amount } \\
\text { of repayment. }\end{array}$ \\
\hline $\begin{array}{l}\text { 7. Should there be full data } \\
\text { transparency towards } \\
\text { external actors? }\end{array}$ & $\begin{array}{l}\text { No. The transactions are primarily private between the customer, } \\
\text { the ESCO company and the investors. These actors have an interest to } \\
\text { protect these sensitive financial data. Additionally, a public authority } \\
\text { might have access to the data, e.g., to monitor and issue white } \\
\text { certificates for efficiency savings. }\end{array}$ \\
\hline $\begin{array}{l}\text { 8. Should there be permissioned } \\
\text { access to the system? }\end{array}$ & $\begin{array}{l}\text { Yes. Only the actors involved in the ESCO project should be able to } \\
\text { transact on the network. All actor groups involved in setting up a new } \\
\text { ESCO project need to be verified and approved. Private investors that } \\
\text { are polled together in a fund might not be individually participating but } \\
\text { represent as a fund. } \\
\text { As this is a novel financial mechanism, there is much regulatory } \\
\text { uncertainty surrounding security tokenisation, and it is important to } \\
\text { stay aligned with regulatory developments. }\end{array}$ \\
\hline
\end{tabular}

A private blockchain is used to protect the sensitive IoT data $[83,84]$, while simultaneously mitigating issues of data integrity and availability $[85,86]$. The application of zero-knowledge proofs enables the granular specification of data access and allows identity verification and transaction processing without the need for revealing any information [116]. Smart contracts are used for cost-efficient microtransactions that are automatically triggered by specific events, i.e., when the repayment of the coupon is due $[85,87,88]$. Through this, even small amounts of coupon sizes can be disseminated to a global investor base at a significantly lower cost compared to fiat alternatives [45,117]. In this way, blockchain technology creates an entirely new distributed economic model by connecting a global investor base with the ESCO project developer.

\section{Discussion}

The decision framework qualitative evaluation shows that the use cases differ in regards to their governance systems, namely in terms of openness of network participation (i.e., permissionless and permissioned) and data privacy (Figure 6). In the cases of P2P energy trading and the ESCO financing 
system, blockchain technology enables novel decentralised governance and organisational models. Through the direct connection of actors, incumbent intermediaries like utilities or banks are removed as centrally facilitating entities, potentially resulting in greater efficiency of the overall system. In the WCS system, blockchain is integrated as an incremental improvement to the system by replacing the data management component. This improvement leads to increased data transparency and reduced costs but does not create a novel governance system.

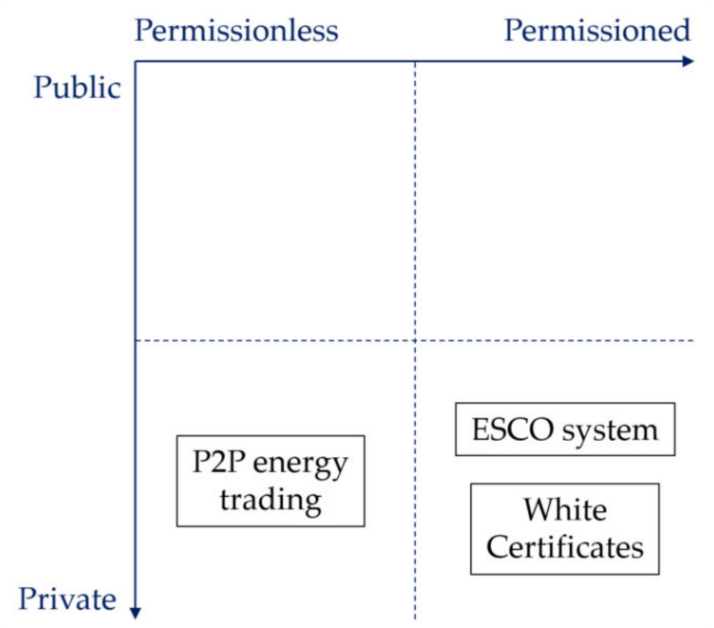

Figure 6. Comparison of governance models of the blockchain case studies.

All three cases use private blockchain applications to protect sensitive data. Data privacy can be achieved by using private blockchains like Hyperledger Fabric or Corda, where reading access is authorised to selected network participants [52,118]. Additionally, other technical encryption methods such as zero-knowledge proof and Zero-Knowledge Succinct Non-Interactive Argument of Knowledge (zkSNARK) can be applied [55,119].

In the current literature, the term blockchain frequently covers a vast array of different blockchain architectures and functions. As each blockchain application is restricted by the blockchain trilemma, the exact balancing of costs and trade-offs needs to be carefully considered. The analysis conducted in this paper shows that each blockchain application varies and is defined by the requirements of each use case. Furthermore, the analysis shows that the blockchain trilemma does not restrict any case application and that the higher costs of an application are more than compensated for by disintermediation gains. Table 4 illustrates the importance of applying a problem-solution fit when considering blockchain so that the appropriate functions and system design are achieved.

In addition to the general benefits of a blockchain application, such as enhanced transparency and reduced transaction costs, the decentralised or democratised organisation of actors can lead to a more efficient allocation of capital due to the inclusion of private (retail) investors and SMEs [114]. It also creates new incentive structures for prosumers to invest in renewable energy sources and purchase locally generated green energy. Moreover, the interactive nature of the P2P grid leads to higher resilience and efficiency, as it incentivises prosumers to adjust their behaviour, rather than being charged an average price. 
Table 4. Use case comparison for blockchain-based approaches.

\begin{tabular}{|c|c|c|c|}
\hline Category & P2P Energy Trading & WCS System & ESCO Financing System \\
\hline System organisation & $\begin{array}{l}\text { Enabling novel interaction } \\
\text { between prosumers }\end{array}$ & $\begin{array}{l}\text { Incremental improvement of } \\
\text { a component in the existing } \\
\text { management system }\end{array}$ & $\begin{array}{l}\text { Enabling novel interaction } \\
\text { between prosumers }\end{array}$ \\
\hline Governance & Private permissionless & Permissioned (private) & Permissioned (private) \\
\hline Application & $\begin{array}{l}\text { Market place for energy } \\
\text { trading }\end{array}$ & $\begin{array}{l}\text { Certification and market } \\
\text { platform }\end{array}$ & Financing mechanism \\
\hline $\begin{array}{l}\text { Legacy system } \\
\text { limitations }\end{array}$ & $\begin{array}{l}\text { - Pricing inefficiencies; } \\
\text { - Monopolised systems } \\
\text { that primarily benefit } \\
\text { the utilities; } \\
\text { Prosumer integration } \\
\text { suffering from distrust, } \\
\text { low security } \\
\text { and inefficiency; } \\
\text { Lack of dynamic grid } \\
\text { energy production and } \\
\text { consumption adjustments; } \\
\text { - Lack of incentives } \\
\text { for prosumers. }\end{array}$ & $\begin{array}{l}\text { - } \quad \text { Lack of transparency; } \\
\text { - } \\
\text { - certification monitoring and } \\
\text { - } \quad \text { Information asymmetry } \\
\text { among actors; } \\
\text { - } \quad \text { Fraudulent behaviour } \\
\text { of actors; } \\
\text { - Availability of reliable } \\
\text { investment data. }\end{array}$ & $\begin{array}{l}\text { - } \quad \text { Access to investments; } \\
\text { - } \quad \text { High transaction costs; } \\
\text { Inhibitive access to } \\
\text { funding for SMEs; } \\
\text { - Counter-party risk for } \\
\text { the repayment of } \\
\text { the loan. }\end{array}$ \\
\hline Benefits & $\begin{array}{l}\text { - } \quad \text { Reduced transaction } \\
\text { costs and } \\
\text { enhanced transparency; } \\
\text { Incentives for } \\
\text { prosumers to use } \\
\text { renewable } \\
\text { energy sources; } \\
\text { Reshaping of prosumer } \\
\text { demand profiles } \\
\text { leading to increased } \\
\text { grid efficiency. }\end{array}$ & $\begin{array}{l}\text { - } \quad \text { Reduced transaction } \\
\text { costs and enhanced } \\
\text { transparency } \\
\text { for certification } \\
\text { Improved fraud } \\
\text { resistance and tracking; } \\
\text { Real-time data for the } \\
\text { regulatory authority to } \\
\text { adjust policy actions. }\end{array}$ & $\begin{array}{l}\text { - Reduced transaction } \\
\text { costs and } \\
\text { enhanced transparency } \\
\text { Access to funding } \\
\text { for SMEs; } \\
\text { - Access to green } \\
\text { investments for private } \\
\text { (retail) investors; } \\
\text { The democratisation } \\
\text { of finance. }\end{array}$ \\
\hline Barriers & $\begin{array}{ll}\text { - } & \text { Regulatory uncertainty; } \\
\text { - } & \text { IoT } \\
\text { tamper vulnerability; } \\
\text { - } & \text { Potential } \\
\text { - } & \text { Scalability limitations; } \\
\text { Potentially opposing } \\
\text { incumbents } \\
\text { (e.g., utility) }\end{array}$ & $\begin{array}{l}\text { - } \quad \text { Regulatory uncertainty; } \\
\text { - IoT } \\
\text { tamper vulnerability. }\end{array}$ & $\begin{array}{ll}\text { - } & \text { Regulatory uncertainty; } \\
\text { - } \quad \text { IoT } & \text { tamper vulnerability; } \\
\text { - } \quad \text { Potentially opposing } \\
\text { incumbents (e.g., } \\
\text { commercial banks). }\end{array}$ \\
\hline
\end{tabular}

However, there are, of course, also uncertainties and barriers to the adoption of these nascent technologies. The integration of IoT sensors can introduce vulnerabilities to the system if it is the primary source of data collection. It is, therefore, essential to triangulate the data with other independent sources to verify the data. Nonetheless, IoT sensors have great potential to mitigate the 'garbage-in, garbage-out' problem due to insufficient data quality [52,54,120], while simultaneously eliminating costly third-party intermediaries [45]. The integration of IoT devices is a key enabler for trusted and reliable distributed monitoring systems by preventing tampering and injection of fake data and enabling the immutable and transparent information sharing among involved untrusted parties [82].

The biggest challenge to blockchain adoption, in general, is the surrounding regulatory uncertainty. While regulatory bodies generally support the active participation of prosumers in the energy market, present regulatory frameworks do not permit the energy trading from prosumers to consumers nor support blockchain as a potential technology [71]. Energy is a critical resource for society, and the transactions in the energy market have always been regulated in order to reduce the risk of potential 
accidents or blackouts. Accordingly, the regulation of the energy market is conservative to safeguard the supply of this crucial resource for society.

As the energy value chain is global, it will be necessary for national or regional governments to coordinate their domestic law and regulation with that of other governments. This interconnection of law and regulation will have an impact on energy actors and regulators in other states, which gives rise to questions related to legitimacy and authority $[14,121]$. Awareness raising and capacity building on the part of policymakers are necessary to develop coherent national and international regulatory frameworks. Researching and piloting of promising blockchain applications provide useful information for policymakers and policy frameworks, while also enabling the maturation of the technology and addressing of current shortfalls.

For this piloting, regulatory sandboxes offer a flexible approach to test and consult with regulators, even though the present regulation might otherwise prohibit implementation of innovative systems [45]. Such regulatory sandboxes "allow practitioners to test innovative products, services, business models and delivery mechanisms in a live environment while being exempt from all the normal regulatory consequences" [122]. An example of such a project in a regulatory sandbox is the T77 P2P energy trading project in Bangkok (more information available at: https://medium.com/power-ledger/case-study-learnmore-about-our-live-project-with-bcpg-in-bangkok-thailand-ab7a31c8b464 (accessed 25 May 2020)).

\section{Conclusions and Future Research}

We show that a blockchain application for accelerating energy efficiency interventions is promising. However, the application has to satisfy the specific use case requirements, and the resulting functions and systems design vary significantly between cases. Hence, we add to the literature by not only enthusiastically promoting new technological options but also advocating for the design of technology and related governance systems to meet the specific requirements of the use cases. This case-driven design is often neglected in the present literature, which uses blockchain mostly as a universal term, but fails to specify among the great variety of blockchain flavours. In this paper, we apply a systematic approach, which can guide the concrete system design, when implementing such systems. This paper aims to raise awareness among energy efficiency practitioners and encourages the development and implementation of pilot studies for the different use cases.

A decentralised system may bring new challenges to the existing framework of energy regulation. However, the results presented in this paper show that blockchain applications offer novel organisational forms and benefits that have the potential to improve and reshape present energy systems significantly. Blockchain technology could stimulate the deployment of energy-efficient products and services for small and large-scale businesses alike, introducing new business models that could improve energy efficiency in the developing world. As depicted in Table 4, we outline the benefits of a blockchain application compared to the traditional systems. By the disintermediating or decentralising of authority in these systems, blockchain can enhance transparency and cost-efficiency. Trust is an essential factor associated with the use of blockchain technology that could reduce investment risk and thus accelerate investments.

This paper demonstrates that blockchain technology can address legacy system constraints that are currently limiting the scaling up of energy efficiency interventions, such as lack of transparency, information asymmetry, high transaction costs, and limited access to finance. Ultimately, in the highly regulated energy market, it will largely depend on regulators, if and how blockchain-based energy systems will evolve.

\section{Research Limitations and Future Research}

Our results illustrate that a blockchain application for all three use cases is promising and how a blockchain-based architecture could accelerate energy efficiency interventions. Despite the great potential, blockchain remains a nascent technology with limited use cases and little empirical data available. Most blockchain propositions are currently only at a conceptual stage. This lack of pilot 
study data limits this paper to a mostly conceptual discussion of potential benefits and constraints of a blockchain application. To date, there are only very few pilot cases available for P2P energy trading, and none for the WCS and ESCO cases. Particularly when dealing with a nascent technology such as blockchain, empirical testing is essential to analyse the true potential. Following Treiblmaier [38], we agree that the theoretical use cases might face additional adoption challenges in practice, which is why the development of blockchain solution requires the incorporation of experiences from practice. To address this, empirical data from pilot studies are essential to validate the suggested conceptual mechanisms and provide evidence of actual system improvements. We therefore strongly recommend the development of pilots, particularly for the WCS and ESCO use cases, for future research to gain insights for both practitioners and policymakers.

Author Contributions: Conceptualisation, M.S. and G.P.D.; methodology, M.S. and A.C.; formal analysis, M.S. and A.C.; writing-original draft preparation, M.S., A.C., and G.P.D.; writing-review and editing, M.S., A.C., G.P.D., and S.S; visualisation, M.S. and A.C; supervision, S.S. All authors have read and agreed to the published version of the manuscript.

Funding: We acknowledge support by the German Research Foundation and the Open Access Publication Fund of TU Berlin.

Acknowledgments: The authors acknowledge the valuable support of Valeria Zambianchi for reference reviews. We would further like to thank Mark Lister, Ksenia Petrichenko and Dan Howis Lauritzen for the initial ideation and feedback on earlier drafts of this paper.

Conflicts of Interest: The authors declare no conflict of interest.

\section{References}

1. In Proceedings of the United Nations Global SDG7 Conference: A Global Preparatory Meeting in Support of the Review of SDG7 at the 2018 UN High Level Political Forum, Bangkok, Thailand, 21-23 February 2018. Available online: https://sustainabledevelopment.un.org/content/sdg7conference/ content/documents/concept_note.pdf. (accessed on 25 May 2020).

2. UNFCCC. Paris Agreement United Nations Framework Convention on Climate Change; UNFCCC: Paris, France, 2015. [CrossRef]

3. UNFCCC. Clean Energy Can Meet 90\% of Paris Energy-Related Goals. 2017. Available online: https: //unfccc.int/news/clean-energy-can-meet-90-of-paris-energy-related-goals (accessed on 27 May 2020).

4. International Energy Agency-IEA. IEA Energy Efficiency 2019; IEA: Paris, France, 2019. Available online: https://www.iea.org/efficiency2019/?utm_content=buffera509e (accessed on 27 May 2020).

5. International Energy Agency-IEA. IEA Energy Efficiency 2018-Analysis and Outlooks to 2040; IEA: Paris, France, 2018. Available online: https://www.iea.org/efficiency2018/ (accessed on 27 May 2020).

6. Cagno, E.; Trianni, A. Evaluating the barriers to specific industrial energy efficiency measures: An exploratory study in small and medium-sized enterprises. J. Clean. Prod. 2014, 82, 70-83. [CrossRef]

7. Henriques, J.; Catarino, J. Motivating towards energy efficiency in small and medium enterprises. J. Clean. Prod. 2016, 139, 42-50. [CrossRef]

8. Gupta, P.; Anand, S.; Gupta, H. Developing a roadmap to overcome barriers to energy efficiency in buildings using best worst method. Sustain. Cities Soc. 2017, 31, 244-259. [CrossRef]

9. Stede, J. Bridging the industrial energy efficiency gap-Assessing the evidence from the Italian white certificate scheme. Energy Policy 2017, 104, 112-123. [CrossRef]

10. Pham, L. Is it risky to go green? A volatility analysis of the green bond market. J. Sustain. Financ. Investig. 2016, 6, 263-291. [CrossRef]

11. Nassiry, D. The Role of Fintech in Unlocking Green Finance. In Handbook of Green Finance; Sachs, J.D., Woo, W.T., Yoshino, N., Taghizadeh-Hesary, F., Eds.; Springer: Singapore, 2019; pp. 1-22, ISBN 9789811302275.

12. Ge, J.; Feng, W.; Zhou, N.; Levine, M.; Szum, C. Accelerating Energy Efficiency in China's Existing Commercial Buildings; Lawrence Berkeley National Laboratory_LBNL: Berkeley, CA, USA, 2017. Available online: https://china.lbl.gov/sites/default/files/lbnl-2001078_accelerating_energy_efficiency_in_ chinas_existing_commercial_buildings___part_1_1219.pdf (accessed on 29 May 2020). 
13. Peimani, H. Financial Barriers to Development of Renewable and Green Energy Projects in Asia. In Handbook of Green Finance; Sachs, J.D., Woo, W.T., Yoshino, N., Taghizadeh-Hesary, F., Eds.; Springer: Singapore, 2019; pp. 1-21, ISBN 9789811302275.

14. Downes, L.; Reed, C. Blockchain for Governance of Sustainability Transparency in the Global Energy Value Chain; Legal Studies Research Paper. No. 283/2018; Queen Mary University of London, School of Law: London, UK, 2018.

15. Khatoon, A.; Verma, P.; Southernwood, J.; Massey, B.; Corcoran, P. Blockchain in Energy Efficiency: Potential Applications and Benefits. Energies 2019, 12, 3317. [CrossRef]

16. Abdella, J.A.; Shuaib, K. An Architecture for Blockchain based Peer to Peer Energy Trading. In Proceedings of the 2019 Sixth International Conference on Internet of Things: Systems, Management and Security (IOTSMS), Granada, Spain, 22-25 October 2019; IEEE: New York, NY, USA, 2019; pp. 412-419.

17. Hwang, J.; Choi, M.I.; Lee, T.; Jeon, S.; Kim, S.; Park, S.; Park, S. Energy Prosumer Business Model Using Blockchain System to Ensure Transparency and Safety. Energy Procedia 2017, 141, 194-198. [CrossRef]

18. Thakur, S.; Breslin, J.G. Peer to Peer Energy Trade Among Microgrids Using Blockchain Based Distributed Coalition Formation Method. Technol. Econ. Smart Grids Sustain. Energy 2018, 3, 5. [CrossRef]

19. Siano, P.; De Marco, G.; Rolan, A.; Loia, V. A Survey and Evaluation of the Potentials of Distributed Ledger Technology for Peer-to-Peer Transactive Energy Exchanges in Local Energy Markets. IEEE Syst. J. 2019, 13, 3454-3466. [CrossRef]

20. Denktas, B.; Pekdemir, S.; Soykan, G. Peer to Peer Business Model Approach for Renewable Energy Cooperatives. In Proceedings of the 2018 7th International Conference on Renewable Energy Research and Applications (ICRERA), Paris, France, 14-17 October 2018; IEEE: New York, NY, USA, 2018; Volume 5, pp. 1336-1339.

21. Morstyn, T.; Farrell, N.; Darby, S.J.; McCulloch, M.D. Using peer-to-peer energy-trading platforms to incentivise prosumers to form federated power plants. Nat. Energy 2018, 3, 94-101. [CrossRef]

22. Di Silvestre, M.L.; Gallo, P.; Guerrero, J.M.; Musca, R.; Riva Sanseverino, E.; Sciumè, G.; Vásquez, J.C.; Zizzo, G. Blockchain for power systems: Current trends and future applications. Renew. Sustain. Energy Rev. 2020, 119, 109585. [CrossRef]

23. Troncia, M.; Galici, M.; Mureddu, M.; Ghiani, E.; Pilo, F. Distributed Ledger Technologies for Peer-to-Peer Local Markets in Distribution Networks. Energies 2019, 12, 3249. [CrossRef]

24. Che, Z.; Wang, Y.; Zhao, J.; Qiang, Y.; Ma, Y.; Liu, J. A Distributed Energy Trading Authentication Mechanism Based on a Consortium Blockchain. Energies 2019, 12, 2878. [CrossRef]

25. Mannaro, K.; Pinna, A.; Marchesi, M. Crypto-trading: Blockchain-oriented energy market. In Proceedings of the 2017 AEIT International Annual Conference, Cagliari, Italy, 20-22 September 2017; IEEE: New York, NY, USA, 2017; pp. 1-5.

26. Diestelmeier, L. Changing power: Shifting the role of electricity consumers with blockchain technology-Policy implications for EU electricity law. Energy Policy 2019, 128, 189-196. [CrossRef]

27. Andoni, M.; Robu, V.; Flynn, D.; Abram, S.; Geach, D.; Jenkins, D.; Mccallum, P.; Peacock, A. Blockchain technology in the energy sector: A systematic review of challenges and opportunities. Renew. Sustain. Energy Rev. 2019, 100, 143-174. [CrossRef]

28. Pop, C.; Cioara, T.; Antal, M.; Anghel, I.; Salomie, I.; Bertoncini, M. Blockchain based decentralised management of demand response programs in smart energy grids. Sensors 2018, 18, 162. [CrossRef]

29. Aitzhan, N.Z.; Svetinovic, D. Security and Privacy in Decentralized Energy Trading Through Multi-Signatures, Blockchain and Anonymous Messaging Streams. IEEE Trans. Dependable Secur. Comput. 2018, 15, 840-852. [CrossRef]

30. Park, L.; Lee, S.; Chang, H. A Sustainable Home Energy Prosumer-Chain Methodology with Energy Tags over the Blockchain. Sustainability 2018, 10, 658. [CrossRef]

31. Martins, J.P.; Ferreira, J.C.; Monteiro, V.; Afonso, J.A.; Afonso, J.L. IoT and Blockchain Paradigms for EV Charging System. Energies 2019, 12, 2987. [CrossRef]

32. Dick, C.I.; Praktiknjo, A. Blockchain technology and electricity wholesale markets: Expert insights on potentials and challenges for OTC trading in Europe. Energies 2019, 12, 832. [CrossRef]

33. Wu, J.; Tran, N.K. Application of blockchain technology in sustainable energy systems: An overview. Sustainability 2018, 10, 3067. [CrossRef] 
34. Huang, L.; Cai, J.; Lee, T.; Weng, M. A Study on the Development Trends of the Energy System with Blockchain Technology Using Patent Analysis. Sustainability 2020, 12, 2005. [CrossRef]

35. Teufel, B.; Sentic, A.; Barmet, M. Blockchain energy: Blockchain in future energy systems. J. Electron. Sci. Technol. 2020, 100011. [CrossRef]

36. Tan, S.; Wang, X.; Jiang, C. Privacy-preserving energy scheduling for ESCOs based on energy blockchain network. Energies 2019, 12, 1530. [CrossRef]

37. Gurcan, O.; Agenis-Nevers, M.; Batany, Y.M.; Elmtiri, M.; Le Fevre, F.; Tucci-Piergiovanni, S. An Industrial Prototype of Trusted Energy Performance Contracts Using Blockchain Technologies. In Proceedings of the 20th International Conference High Performance Computing and Communications, 16th International Conference Smart City, 4th International Conference Data Science and Systems (HPCC/SmartCity/DSS), Exeter, UK, 28-30 June 2018; Volume I, pp. 1336-1343. [CrossRef]

38. Treiblmaier, $\mathrm{H}$. The impact of the blockchain on the supply chain: A theory-based research framework and a call for action. Supply Chain Manag. Int. J. 2018, 23, 545-559. [CrossRef]

39. Chang, S.E.; Chen, Y.; Lu, M.; Luo, H.L. Development and Evaluation of a Smart Contract-Enabled Blockchain System for Home Care Service Innovation: Mixed Methods Study. JMIR Med. Inform. 2020, 8, 15. [CrossRef]

40. Du, M.; Chen, Q.; Chen, J.; Ma, X. An Optimised Consortium Blockchain for Medical Information Sharing. IEEE Trans. Eng. Manag. 2020, 1-13. [CrossRef]

41. Hackius, N.; Petersen, M. Translating High Hopes Into Tangible Benefits: How Incumbents in Supply Chain and Logistics Approach Blockchain. IEEE Access 2020, 8, 34993-35003. [CrossRef]

42. Dai, J.; Vasarhelyi, M.A. Toward Blockchain-Based Accounting and Assurance. J. Inf. Syst. 2017, 31, 5-21. [CrossRef]

43. Kewell, B.; Adams, R.; Parry, G. Blockchain for good? Strateg. Chang. 2017, 26, 429-437. [CrossRef]

44. Bano, S.; Sonnino, A.; Al-bassam, M.; Azouvi, S.; Mccorry, P. SoK: Consensus in the Age of Blockchains. arXiv 2017, arXiv:arXivabs/1711.03936v2. Available online: https://arxiv.org/abs/1711.03936v2 (accessed on 29 January 2020).

45. Schletz, M.; Nassiry, D.; Lee, M.-K. Blockchain and Tokenized Securities: The Potential for Green Finance; ADBI Working Papers; ADBI Institute: Tokyo, Japan, 2020. Available online: https://www.adb.org/publications/ blockchain-tokenized-securities-potential-green-finance. (accessed on 1 February 2020).

46. Cong, L.W.; He, Z. Blockchain Disruption and Smart Contracts. Rev. Financ. Stud. 2019, 32, $1754-1797$. [CrossRef]

47. Walsh, C.; O’Reilly, P.; Gleasure, R.; Feller, J.; Shanping, L.; Cristoforo, J. New kid on the block: A strategic archetypes approach to understanding the Blockchain. In Proceedings of the ICIS 2016 Proceedings, Dublin, Ireland, 11-14 December 2016; Association for Information Systems (AIS): Atlanta, GA, USA, 2016; pp. 1-12.

48. Risius, M.; Spohrer, K. A Blockchain Research Framework: What We (don't) Know, Where We Go from Here, and How We Will Get There. Bus. Inf. Syst. Eng. 2017, 59, 385-409. [CrossRef]

49. Abdella, J.; Shuaib, K. Peer to peer distributed energy trading in smart grids: A survey. Energies 2018, 11, 1560. [CrossRef]

50. Franke, L.; Schletz, M.; Salomo, S. Designing a Blockchain Model for the Paris Agreement's Carbon Market Mechanism. Sustainability 2020, 12, 1068. [CrossRef]

51. Peters, G.W.; Panayi, E. Understanding modern banking ledgers through blockchain technologies: Future of transaction processing and smart contracts on the internet of money. New Econ. Wind. 2016, 239-278. [CrossRef]

52. Duchenne, J. Blockchain and Smart Contracts: Complementing Climate Finance, Legislative Frameworks, and Renewable Energy Projects. In Transforming Climate Finance and Green Investment with Blockchains; Marke, A., Ed.; Academic Press: Cambridge, MA, USA, 2018; p. 368, ISBN 9780128144473.

53. Dong, X.; Mok, R.C.K.; Tabassum, D.; Guigon, P.; Ferreira, E.; Sinha, C.S.; Prasad, N.; Madden, J.; Baumann, T.; Libersky, J.; et al. Blockchain and Emerging Digital Technologies for Enhancing Post-2020 Climate Markets; World Bank Group: Washington, DC, USA, 2018. Available online: http://documents.worldbank.org/curated/en/942981521464296927/Blockchain-and-emerging-digitaltechnologies-for-enhancing-post-2020-climate-markets (accessed on 25 February 2019).

54. Skovgaard, J.; Ferrari, S.S.; Knaggård, Å. Mapping and clustering the adoption of carbon pricing policies: What polities price carbon and why? Clim. Policy 2019, 19, 1173-1185. [CrossRef] 
55. Schletz, M.; Franke, L.; Salomo, S. Blockchain Application for the Paris Agreement Carbon Market Mechanism-A Decision Framework and Architecture. Sustainability 2020, 12, 5069. [CrossRef]

56. CLI. Navigating Blockchain and Climate Action 2019 State and Trends; Climate Ledger Initiative: Zurich, Switzerland, 2019; p. 72. Available online: https://www.climateledger.org/en/News.3.html?nid=33 (accessed on 30 April 2020).

57. Howson, P. Tackling climate change with blockchain. Nat. Clim. Chang. 2019. [CrossRef]

58. Marjani, M.; Nasaruddin, F.; Gani, A.; Karim, A.; Hashem, I.A.T.; Siddiqa, A.; Yaqoob, I. Big IoT Data Analytics: Architecture, Opportunities, and Open Research Challenges. IEEE Access 2017, 5, 5247-5261. [CrossRef]

59. Kiviat, T.I. Beyond Bitcoin: Issues in Regulating Blockchain Transactions. Duke Law J. 2015, 65, 569-608. Available online: https://scholarship.law.duke.edu/dlj/vol65/iss3/4/ (accessed on 6 June 2020).

60. Baumann, T. Blockchain for Planetary Stewardship: Using the Disruptive Force of Distributed Ledger to Fight Climate Disruption. Blockchain Res. Inst. 2018, 1, 34.

61. Blakstad, S.; Allen, R. Green Fintech. Universal Inclusion in the New Financial Ecosystem. In FinTech Revolution; Springer International Publishing: Cham, Switzerland, 2018; pp. 183-199, ISBN 9783319760148.

62. Tushar, W.; Saha, T.K.; Yuen, C.; Morstyn, T.; Al-Masood, N.; Poor, H.V.; Bean, R. Grid Influenced Peer-to-Peer Energy Trading. IEEE Trans. Smart Grid 2019, 11, 1407-1418. [CrossRef]

63. Nguyen, V.H.; Besanger, Y.; Tran, Q.T.; Le, M.T. On the Applicability of Distributed Ledger Architectures to Peer-to-Peer Energy Trading Framework. In Proceedings of the 2018 IEEE International Conference on Environment and Electrical Engineering and 2018 IEEE Industrial and Commercial Power Systems Europe (EEEIC/I\&CPS Europe), Palermo, Italy, 12-15 June 2018; IEEE: New York, NY, USA, 2018; pp. 1-5.

64. Di Santo, D.; Biele, E.; De Chicchis, L. White certificates as a tool to promote energy efficiency in industry. In Proceedings of the Eceee Summer Studies, Industrial Efficiency 2018 Leading the Low-Carbon Transition, Berlin, Germany, 11-13 June 2018; pp. 43-53.

65. CLI. Blockchain Potentials and Limitations for Selected Climate Policy Instruments. Climate Ledger Initiative: Zurich, Switzerland, 2019. Available online: https:/www.giz.de/en/downloads/giz2019-EN-BlockchainPotentials-Climate-Policy.pdf (accessed on 8 May 2019).

66. Born, R. Distributed Ledger Technology for Climate Action Assessment; EIT Climate-KIC: Zurich, Switzerland, 2018; pp. 1-129.

67. Yu, G.; Wang, X.; Zha, X.; Zhang, J.A.; Liu, R.P. An Optimized Round-Robin Scheduling of Speakers for Peers-to-Peers-Based Byzantine Faulty Tolerance. In Proceedings of the 2018 IEEE Globecom Workshops (GC Wkshps), Abu Dhabi, UAE, 9-13 December 2018; IEEE: New York, NY, USA, 2019; pp. 1-6.

68. Rocha, R.; Villar, J.; Bessa, R.J. Business models for Peer-to-Peer Energy Markets. In Proceedings of the 2019 16th International Conference on the European Energy Market (EEM), Ljubljana, Slovenia, 18-20 September 2019; IEEE: New York, NY, USA, 2019; pp. 1-6.

69. Schleicher-Tappeser, R. How renewables will change electricity markets in the next five years. Energy Policy 2012, 48, 64-75. [CrossRef]

70. Serpell, O. Energy and the Blockchain: Opportunities and Challenges for Climate and Energy Governance; Kleiman Center for Energy Policy-University of Pennsylvania School of Design: Philadelphia, PA, USA, 2018. Available online: https://kleinmanenergy.upenn.edu/sites/default/files/policydigest/Energy\%20and\%20the\% 20Blockchainpdf (accessed on 13 May 2020).

71. Alladi, T.; Chamola, V.; Rodrigues, J.J.P.C.; Kozlov, S.A. Blockchain in Smart Grids: A Review on Different Use Cases. Sensors 2019, 19, 4862. [CrossRef] [PubMed]

72. Hassija, V.; Bansal, G.; Chamola, V.; Saxena, V.; Sikdar, B. BlockCom: A Blockchain Based Commerce Model for Smart Communities using Auction Mechanism. In Proceedings of the 2019 IEEE International Conference on Communications Workshops (ICC Workshops), Shanghai, China, 22-24 May 2019; IEEE: New York, NY, USA, 2019; pp. 1-6.

73. Bansal, G.; Hasija, V.; Chamola, V.; Kumar, N.; Guizani, M. Smart Stock Exchange Market: A Secure Predictive Decentralized Model. In Proceedings of the 2019 IEEE Global Communications Conference (GLOBECOM), Waikoloa, HI, USA, 9-13 December 2019; IEEE: New York, NY, USA, 2019; pp. 1-6.

74. Sioshansi, F.P. Electricity Market Reform: What Have We Learned? What Have We Gained? Electr. J. 2006, 19, 70-83. [CrossRef] 
75. Wainstein, M.E.; Bumpus, A.G. Business models as drivers of the low carbon power system transition: A multi-level perspective. J. Clean. Prod. 2016, 126, 572-585. [CrossRef]

76. McConnell, D.; Hearps, P.; Eales, D.; Sandiford, M.; Dunn, R.; Wright, M.; Bateman, L. Retrospective modeling of the merit-order effect on wholesale electricity prices from distributed photovoltaic generation in the Australian National Electricity Market. Energy Policy 2013, 58, 17-27. [CrossRef]

77. Zhang, C.; Wu, J.; Zhou, Y.; Cheng, M.; Long, C. Peer-to-Peer energy trading in a Microgrid. Appl. Energy 2018, 220, 1-12. [CrossRef]

78. Delarestaghi, J.M.; Arefi, A.; Ledwich, G. The impact of peer to peer market on energy costs of consumers with pv and battery. In Proceedings of the 2018 IEEE PES Innovative Smart Grid Technologies Conference Europe (ISGT-Europe), Sarajevo, Bosnia and Herzegovina, 21-25 October 2018; IEEE: New York, NY, USA, 2018; pp. 1-6.

79. IEA. Capturing the Multiple Benefits of Energy Efficiency; International Energy Agency: Paris, France, 2014. Available online: https://renovate-europe.eu/wp-content/uploads/2015/10/Campbell_REDay2014_Final.pdf (accessed on 20 October 2020).

80. IEA. Multiple Benefits of Energy Efficiency; International Energy Agency: Paris, France, 2019. Available online: https://www.iea.org/reports/multiple-benefits-of-energy-efficiency (accessed on 20 October 2020).

81. Gökgöz, F.; Güvercin, M.T. Energy security and renewable energy efficiency in EU. Renew. Sustain. Energy Rev. 2018, 96, 226-239. [CrossRef]

82. Nguyen, L.D.; Kalør, A.E.; Leyva-Mayorga, I.; Popovski, P. Trusted Wireless Monitoring based on Distributed Ledgers over NB-IoT Connectivity. arXiv 2020, arXiv:2004.06299. Available online: https://arxiv.org/abs/2004. 06299 (accessed on 20 May 2020).

83. Sicari, S.; Rizzardi, A.; Grieco, L.A.; Coen-Porisini, A. Security, privacy and trust in Internet of things: The road ahead. Comput. Netw. 2015, 76, 146-164. [CrossRef]

84. Lowry, P.B.; Dinev, T.; Willison, R. Why security and privacy research lies at the centre of the information systems (IS) artefact: Proposing a bold research agenda. Eur. J. Inf. Syst. 2017, 26, 546-563. [CrossRef]

85. Ali, M.S.; Vecchio, M.; Pincheira, M.; Dolui, K.; Antonelli, F.; Rehmani, M.H. Applications of Blockchains in the Internet of Things: A Comprehensive Survey. IEEE Commun. Surv. Tutor. 2019, 21, 1676-1717. [CrossRef]

86. Chanson, M.; Bogner, A.; Bilgeri, D.; Fleisch, E.; Wortmann, F. Blockchain for the IoT: Privacy-Preserving Protection of Sensor Data. J. Assoc. Inf. Syst. 2019, 20, 1272-1307. [CrossRef]

87. Cocco, L.; Pinna, A.; Marchesi, M. Banking on blockchain: Costs savings thanks to the blockchain technology. Future Internet 2017, 9, 25. [CrossRef]

88. Beck, R.; Czepluch, J.S.; Lollike, N.; Malone, S. Blockchain-The gateway to trust-free cryptographic transactions. In Proceedings of the 24th European Conference on Information Systems, ECIS 2016, Istanbul, Turkey, 12-15 June 2016; pp. 1-14.

89. Rogers, E.A.; Carley, E.; Deo, S.; Grossberg, F. How Information and Communications Technologies Will Change the Evaluation, Measurement, and Verification of Energy Efficiency Programs; American Council for an Energy-Efficient Economy: Washington, DC, USA, 2015.

90. Billimoria, S.; Henchen, M.; Guccione, L.; Louis-Prescott, L. The Economics of Electrifying Buildings: How Electric Space and Water Heating Supports Decarbonization of Residential Buildings; Technical Report; Rocky Mountain Institute: Basalt, CO, USA, 2018.

91. Liu, N.; Yu, X.; Wang, C.; Li, C.; Ma, L.; Lei, J. Energy-Sharing Model With Price-Based Demand Response for Microgrids of Peer-to-Peer Prosumers. IEEE Trans. Power Syst. 2017, 32, 3569-3583. [CrossRef]

92. Consensys Ethereum 2.0 FAQ. An Overview of Questions, Additional Resources, and Products Relating to Ethereum 2.0 and Staking on the Beacon Chain in 2020. Available online: https://consensys.net/knowledgebase/ethereum-2/faq (accessed on 15 July 2020).

93. Gorenflo, C.; Lee, S.; Golab, L.; Keshav, S. FastFabric: Scaling Hyperledger Fabric to 20,000 Transactions per Second. arXiv 2019, arXiv:1901.00910. Available online: https://arxiv.org/abs/1901.009 (accessed on 20 May 2020).

94. European Commission. The Energy Efficiency Directive (2012/27/EU). Available online: https://ec.europa. eu/energy/en/topics/energy-efficiency/targets-directive-and-rules/energy-efficiency-directive (accessed on 15 July 2020).

95. Fawcett, T.; Rosenow, J.; Bertoldi, P. Energy efficiency obligation schemes: Their future in the EU. Energy Effic. 2019, 12, 57-71. [CrossRef] 
96. Aldrich, E.L.; Koerner, C.L. White certificate trading: A dying concept or just making its debut? Part I: Market status and trends. Electr. J. 2018, 31, 52-63. [CrossRef]

97. Lacas, F. Energy Savings Certificates: Fraud Alert. Available online: https://www.batiactu.com/edito/fraudeaux-cee-millions-euros-jeu-51295.php (accessed on 4 November 2019).

98. Connolly, T.M.; Begg, C.E. Database Systems: A Practical Approach to Design, Implementation, and Management, 6th ed.; Pearson: Boston, MA, USA, 2015.

99. Elmasri, R.; Navathe, S.B. Fundamentals of Database Systems, 7th ed.; Pearson Education: Boston, MA, USA, 2016; ISBN 978-0133970777.

100. Notheisen, B.; Cholewa, J.B.; Shanmugam, A.P. Trading Real-World Assets on Blockchain: An Application of Trust-Free Transaction Systems in the Market for Lemons. Bus. Inf. Syst. Eng. 2017, 59, 425-440. [CrossRef]

101. Danzi, P.; Kalor, A.E.; Sorensen, R.B.; Hagelskjær, A.K.; Nguyen, L.D.; Stefanovic, C.; Popovski, P. Communication Aspects of the Integration of Wireless IoT Devices with Distributed Ledger Technology [arXiv]. IEEE Netw. 2020, 34, 47-53. [CrossRef]

102. Sanderson, O. How to Trust Green Bonds. In Transforming Climate Finance and Green Investment with Blockchains; Marke, A., Ed.; Academic Press: Cambridge, MA, USA, 2018; p. 368, ISBN 9780128144473.

103. Merrill, R.K.; Schillebeeckx, S.J.; Blakstad, S. Sustainable Digital Finance in Asia: Creating Environmental Impact through Bank Transformation; Sustainable Digital Finance Alliance-SDFA: Riyadh, Saudi Arabia, 2019.

104. Androulaki, E.; Bortnikov, V.; Cachin, C.; De Caro, A.; Enyeart, D.; Muralidharan, S.; Murthy, C.; Smith, K.; Sorniotti, A.; Cocco, S.W.; et al. Hyperledger Fabric: A Distributed Operating System for Permissioned Blockchains. arXiv 2018, arXiv:1801.10228. Available online: https://arxiv.org/abs/1801.10228 (accessed on 24 January 2020). [CrossRef]

105. Chen, Y.; Gong, X.; Chu, C.C.; Cao, Y. Access to the Internet and Access to Finance: Theory and Evidence. Sustainability 2018, 10, 2534. [CrossRef]

106. Rühmann, F.; Konda, S.A.; Horrocks, P.; Taka, N. Can Blockchain Technology Reduce the Cost of Remittances? OECD Development Co-operation Working Papers; OECD: Paris, France, 2020. Available online: https://www.oecd-ilibrary.org/development/can-blockchain-technology-reduce-the-costof-remittances_d4d6ac8f-en (accessed on 27 April 2020).

107. Antipova, T. Using blockchain technology for government auditing. In Proceedings of the 2018 13th Iberian Conference on Information Systems and Technologies (CISTI), Caceres, Spain, 13-16 June 2018; IEEE: New York, NY, USA, 2018; pp. 1-6.

108. Abreu, P.W.; Aparicio, M.; Costa, C.J. Blockchain technology in the auditing environment. In Proceedings of the 2018 13th Iberian Conference on Information Systems and Technologies (CISTI), Caceres, Spain, 13-16 June 2018; IEEE: New York, NY, USA, 2018; pp. 1-6.

109. Ashley, M.J.; Johnson, M. Establishing a Secure, Transparent, and Autonomous Blockchain of Custody for Renewable Energy Credits and Carbon Credits. IEEE Eng. Manag. Rev. 2018, 46, 100-102. [CrossRef]

110. Tupikina, A.A.; Rozhkova, M.V. Economic Evaluation of Energy Service Contract Implementation from the View of its Participants. In Proceedings of the 2018 14th International Scientific-Technical Conference on Actual Problems of Electronics Instrument Engineering (APEIE 2018), Novosibirsk, Russia, 2-6 October 2018; pp. 459-463. [CrossRef]

111. Bertoldi, P.; Boza-Kiss, B. Analysis of barriers and drivers for the development of the ESCO markets in Europe. Energy Policy 2017, 107, 345-355. [CrossRef]

112. Oliveira, L.; Bauer, I.; Schwabe, G. To Token or not to Token: Tools for Understanding Blockchain Tokens. In Proceedings of the Thirty Ninth International Conference on Information Systems, San Francisco, CA, USA, 13-16 December 2018; pp. 1-17.

113. Pilkington, M. Blockchain Technology: Principles and Applications. In Research Handbook on Digital Transformations; Xavier, F., Zhegu, O.M., Eds.; Edward Elgar Publishing: London, UK, 2015; pp. 1-39.

114. OECD. The Tokenisation of Assets and Potential Implications for Financial Markets; OECD Blockchain Policy Series; Organisation for Economic Co-Operation and Development: Paris, France, 2020.

115. Thomason, J.; Ahmad, M.; Bronder, P.; Hoyt, E.; Pocock, S.; Bouteloupe, J.; Donaghy, K.; Huysman, D.; Willenberg, T.; Joakim, B.; et al. Blockchain-Powering and Empowering the Poor in Developing Countries. In Transforming Climate Finance and Green Investment with Blockchains; Marke, A., Ed.; Academic Press: Cambridge, MA, USA, 2018; p. 368, ISBN 9780128144473. 
116. He, D.; Leckow, R.; Haksar, V.; Mancini-Griffoli, T.; Jenkinson, N.; Kashima, M.; Khiaonarong, T.; Rochon, C.; Tourpe, H.; Adrian, T.; et al. Fintech and Financial Services: Initial Considerations; International Monetary Fund: Washington, DC, USA, 2017; p. 49.

117. Varma, J.R. Blockchain in Finance. Vikalpa J. Decis. Makers 2019, 44, 1-11. [CrossRef]

118. Pedersen, A.B.; Risius, M.; Beck, R. Blockchain Decision Path: “When To Use Blockchain?"- "Which Blockchain Do You Mean?" MIS Q. Exec. 2019, 18, 24.

119. Reitwiessner, C. zkSNARKs in a Nutshell. Ethereum Blog 2016, 6, 1-15.

120. CLI. Navigating Blockchain and Climate Action. An Overview; Climate Ledger Initiative: Zurich, Switzerland, 2018; p. 88.

121. Reed, C.; Murray, A. Rethinking the Jurisprudence of Cyberspace; Edward Elgar Publishing: London, UK, 2018; ISBN 9781785364280.

122. World Bank Group. Distributed Ledger Technology (DLT) and Blockchain; World Bank Group: Washington, DC, USA, 2017. [CrossRef]

Publisher's Note: MDPI stays neutral with regard to jurisdictional claims in published maps and institutional affiliations.

(C) 2020 by the authors. Licensee MDPI, Basel, Switzerland. This article is an open access article distributed under the terms and conditions of the Creative Commons Attribution (CC BY) license (http://creativecommons.org/licenses/by/4.0/). 